\title{
Soluble factors regulated by epithelial-mesenchymal transition mediate tumour angiogenesis and myeloid cell recruitment
}

Meggy Suarez-Carmona ${ }^{1,2}$, Morgane Bourcy ${ }^{1}$, Julien Lesage ${ }^{3}$, Natacha Leroi ${ }^{1}$, Laïdya Syne ${ }^{1}$, Silvia Blacher ${ }^{1}$, Pascale Huber $^{2}$, Charlotte Erpicum ${ }^{2}$, Jean-Michel Foidart ${ }^{1}$, Philippe Delvenne $^{2}$, Philippe Birembaut ${ }^{3}$, Agnès Noël ${ }^{1}$, Myriam Polette $^{3}$ and Christine Gilles ${ }^{1}$.

${ }^{1}$ Laboratory of Tumor and Development Biology (LTDB) GIGA-Cancer, Liège, Belgium.

${ }^{2}$ Laboratory of Experimental Pathology (LEP) GIGA-Cancer, Liège, Belgium.

${ }^{3}$ INSERM UMR-S 903, Laboratoire Pol Bouin, University of Reims, France.

The authors have no conflict of interest to declare.

Author to whom correspondence, proofs and reprint requests should be sent:

Dr Christine Gilles

Laboratory of Tumor and Development Biology (LBTD), GIGA-Cancer

Tour de Pathologie, B23, +4 CHU Sart Tilman,University of Liège, 4000 Liège, Belgium

Tel: $0032(0) 43662453$

Fax: $0032(0) 43662936$

Email: cgilles@ulg.ac.be

This article has been accepted for publication and undergone full peer review but has not been through the copyediting, typesetting, pagination and proofreading process, which may lead to differences between this version and the Version of Record. Please cite this article as doi: $10.1002 /$ path. 4546 


\begin{abstract}
Epithelial-to-mesenchymal transition (EMT) programs provide cancer cells with invasive and survival capacities that might favor metastatic dissemination. Whilst signaling cascades triggering EMT have been extensively studied, the impact of EMT on the crosstalk between tumor cells and the tumor microenvironment remains elusive. We aimed to identify EMTregulated soluble factors that facilitate the recruitment of host cells in the tumor. Our findings indicate that EMT phenotypes relate to the induction of a panel of secreted mediators, namely IL-8, IL-6, sICAM-1, PAI-1 and GM-CSF, and implicate the EMT-transcription factor Snail as a regulator of this process. We further show that EMT-derived soluble factors are proangiogenic in vivo (in the mouse ear sponge assay), ex vivo (in the rat aortic ring assay) and in vitro (in a chemotaxis assay). Additionally, conditioned medium from EMT-positive cells stimulates the recruitment of myeloid cells. In a bank of 40 triple-negative breast cancers, tumors presenting features of EMT were significantly more angiogenic and infiltrated by a higher quantity of myeloid cells compared to tumors with little or no EMT. Taken together, our results show that EMT programs trigger the expression of soluble mediators in cancer cells that stimulate angiogenesis and recruit myeloid cells in vivo, which might in turn favor cancer spread.
\end{abstract}

Keywords: epithelial-to-mesenchymal transition, cancer, angiogenesis, myeloid cells 


\section{Introduction}

Known as developmental programs transforming epithelial cells into mesenchymal cells $[1,2]$, epithelial-to-mesenchymal transitions (EMT) trigger a morphological switch from a cobblestone shape to an elongated form, alongside decreased expression of epithelial markers (i.e. E-cadherin) and gains of mesenchymal markers (i.e. vimentin) [3, 4]. A variety of EMTinducing extracellular signals and signaling pathways converge to induce expression of EMTtranscription factors (EMT-TF) [5, 6] including those of the Snail family (Snail and Slug), ZEB1 and ZEB2, Twist, E47, Brachyury and others. Although a major and well-described effect of EMT-TFs is E-cadherin repression [6-8], EMT-TFs can activate or repress a variety of target genes [9-11] ([12] for a review). In the most studied Snail family, the two human homologs Snail and Slug contain a Zinc finger cluster enabling interaction with specific DNA sequences called E-boxes, first discovered on the chd1/E-cadherin promoter $[7,13]$. Snail expression is connected to disease progression, for instance with lymph node metastasis in breast cancer [14] and with poor overall survival in ovarian cancer [15]. In mouse models, Snail has been shown to trigger inflammation and hyperplasia followed by tumor formation [16], to accelerate metastasis through enhanced invasion and immunosuppression [17] and to increase blood vessel density [18]. Snail has also been associated to cancer stemness in colorectal cancer cells [19].

Partial, reversible EMT has been suggested to occur at different steps of cancer progression $[3,20-22]$ and recent findings indicate that EMT is particularly involved in tumor cell escape from the primary tumor and the release of circulating tumor cells (CTCs) [23, 24]. CTCs from breast cancer patients have accordingly been shown to express EMT markers [20, $25,26]$ and EMT-derived phenotypes are observed in about $15 \%$ of invasive ductal carcinomas and relate to higher histological grade, higher rate of loco-regional recurrence [8], chemoresistance [27] and presence of lymph node metastases [14]. EMT markers are 
particularly associated with triple-negative breast cancers (TNBCs) [14, 28-30], an aggressive subgroup for which there is no efficient therapy as yet [31].

Although the cellular pathways leading to EMT and their contribution to intrinsically enhanced invasive properties of tumor cells have been extensively studied, the impact of EMT programs on the crosstalk between tumor cells and the tumor microenvironment remains elusive. Yet, metastatic dissemination largely relies on tumor-stroma interactions and cytokines represent major soluble mediators implicated in tumor-stroma crosstalk [32-34]. Cytokine overexpression by cancer cells has been reported in many cancers including breast and lung [35-37], although the mechanisms involved are still largely uncovered. We hypothesized that EMT programs modulate the microenvironment, thereby stimulating recruitment of a variety of host cells and elaborating a permissive milieu for tumor progression. 


\section{Materials and methods}

\section{Immunohistochemical study on human samples}

Human breast tissues were obtained from 40 biopsies of ductal invasive triple-negative breast carcinomas from Reims University Hospital Biological Resource Collection n DC-2008-374 and staged according to the 2009 WHO classification. This study was approved by the Institutional Review Board of Reims University Hospital. Antibodies used for immunohistochemistry are provided in supplemental Table S1. Semi-quantitative scoring methods are described in Supplemental materials and methods.

\section{Cell culture and growth factor induction of EMT}

Cancer cell lines were from ATCC (American Type Culture Collection, Manassas, VA). The A549 and MDA-MB-468 cells used are luciferase-expressing clones purchased (Caliper Life Sciences, Hopkinton, MA) and generated as previously described [21]. A description of culture reagents is provided in Supplemental materials and methods. MDA-MB-468 and A549 were seeded $\left(2 \times 10^{5}\right.$ and $1.5 \times 10^{5}$ cells respectively) in 6-well plates and immediately treated with $20 \mathrm{ng} / \mathrm{ml}$ recombinant EGF (Sigma, St-Louis, MO) or $5 \mathrm{ng} / \mathrm{ml}$ recombinant TGF- $\beta$ (R\&D Systems, Minneapolis, MN) respectively. Twenty four hours after seeding, the medium was replaced by serum-free medium (complemented or not with EGF or TGF- $\beta$ ) and left 24 supplemental hours. Conditioned media were then collected and RNA extracted. A detailed procedure for subsequent cytokine array is provided in Supplemental materials and methods. 


\section{Plasmid and siRNA transfections}

Cells were seeded as described above and transfected 48 hours later in serum-free medium with Lipofectamine RNAiMax (Life Technologies, Carlsbad, CA). SiRNA sequences are provided in Supplemental materials and methods. Plasmids were transfected using the ExtremeGENE 9 reagent (Roche, Basel, Switzerland) in serum-free medium and RNA was extracted 48 hours later. The plasmids used were pCMV-Tag2B Snail-6SA (Addgene, Cambridge, MA, USA) and pCMV-Tag2B as an empty control vector.

\section{Recombinant proteins, ELISA, Reverse Transcription and PCR}

Recombinant IL-8 was from R\&D and recombinant ICAM-1 from Peprotech (Hamburg, Germany). The IL-6 ELISA kit was a Cytoset kit (Invitrogen, Carlsbad, California). Other ELISAs were performed with Duoset kits (R\&D). After RNA extraction (High Pure RNA Isolation Kit, Roche) and reverse transcription (First Strand cDNA Synthesis kit, Roche), real time PCR was performed with the LightCycler480 Probes Master kit and the Universal Probe Library system (Roche). Alternatively, endpoint PCR was performed for a defined number of PCR cycles after which amplicons were separated on acrylamide gels stained with GelStar (Lonza, Basel, Switzerland). Primer sequences are provided in Supplemental Table S2. Gene expression was normalized to GAPDH (glyceraldehyde-3-phosphate dehydrogenase) or to TBP (TATA-box binding protein).

\section{Sponge assay, immunofluorescence and FACS}

Sponge assays were performed as previously described [38]. Briefly, gelfoam sponges (Pfizer, New-York, NY) were soaked in conditioned medium concentrated with Amicon 
filters (Millipore, Darmstadt, Germany). We used conditioned medium from non-treated (“C") or EGF-treated MDA-MB-468 ("EGF") or from non-treated (“C”) or TGF- $\beta$-treated A549 ("TGF- $\beta$ "). To exclude EGF or TGF- $\beta$ direct effects on host cell recruitment, remaining levels of EGF and TGF- $\beta$ in the treated conditions were measured by ELISA and the equivalent amounts were added into corresponding conditioned medium of untreated cells, yielding " $\mathrm{C}+\mathrm{E}$ " and " $\mathrm{C}+\mathrm{T}$ " conditions used as controls in all experiments. Experimente including the control medium without addition of EGF ("C") were also performed. Sponges were subcutaneously inserted into the ears of C57BL/6 mice (Charles River, Chatillon-surChalarone, France) and left for 3 days or 3 weeks. In some experiments, concentrated conditioned medium from EGF-treated MDA-MB-468 was pre-incubated overnight with blocking antibody (Supplemental Table S1) or the corresponding negative control antibody (Dako, Glostrup, Denmark), before depletion by immunoprecipitation using protein-Gcoupled Dynabeads (Lifetechnologies). A description of ear processing, staining and computer-assisted quantification of angiogenesis and myeloid cell distribution is provided in

Supplemental materials and methods. For FACS, sponges were collected and dissociated using PBS-EDTA for 10 minutes at $37^{\circ} \mathrm{C}$. Sponge isolates and flushed bone marrows were centrifuged and suspended in PBS containing 3\% serum, filtered and processed for staining. Antibodies are listed in Supplemental Table S1.

\section{Aortic ring assays and transwell migration assays}

The protocol for aortic ring assays has been described [39] and is detailed in Supplemental materials and methods. For migration assays, HUVECs $\left(10^{5}\right.$ cells in serum-free medium containing $0.1 \%$ BSA) were placed in the upper compartment of a Transwell (Corning, Tewksbury, MA). The lower compartment was filled with conditioned media containing $1 \%$ 
BSA. For inhibitory experiments, media were pre-incubated with blocking antibodies (Supplemental Table S1) or negative control antibodies (Dako). After 24h of migration through an $8 \mu \mathrm{m}$-pore gelatin-coated filter, cells were fixed and stained with Giemsa. The upper side of the membranes was scraped to remove non migrating cells. Conditions were run in triplicates. Image processing for quantification is described in Supplemental materials and methods.

\section{Laser-Capture Microdissection on MDA-MB-468 xenografts}

MDA-MB-468 cell tumors were grown for 100 days following subcutaneous injection in SCID mice as previously described [21]. Tumors were embedded in OCT (VWR, Radnor, PA). Microdissection was performed based on vimentin staining on a serial reference slide as previously described [21] using the Leica LMD7000 (GIGA-Imaging platform) and followed by RNA extraction (TriZOL, Invitrogen) and purification (RNeasy mini kit, Qiagen Valencia, CA).

\section{Statistical analyses}

Statistical analysis was performed with the Prism software (Graphpad Software, San Diego, CA). For immunohistochemistry on human samples, associations between the different markers were studied using Fisher exact tests. Otherwise, results were analyzed with the nonparametric Mann Whitney test with one-tailed p-value. A p-value $<0.05$ was considered significant. In histograms, mean $\pm \mathrm{SEM}$ is represented. 


\section{Results}

\section{EMT phenotypes induce a panel of soluble factors in vitro and in vivo}

To examine whether EMT programs are involved in the regulation of potential soluble modulators of angiogenesis and inflammation, two human models of inducible EMT were used: the MDA-MB-468 mammary adenocarcinoma cell line and the A549 lung carcinoma cell line, in which EMT was induced by EGF or TGF- $\beta$ respectively. In MDA-MB-468, a detailed characterization of EGF-induced EMT has been published previously [21]. We here confirmed EMT induction by observation of morphological changes (Figure 1A) and by RTqPCR, showing a decrease in E-cadherin and an increase in vimentin mRNA levels (Figure 1B). In A549, TGF- $\beta$ treatment induced morphological changes (Supplemental Figure S1A), a decrease in epithelial markers (i.e. E-cadherin, Cingulin and ZO-3,) and an increase in mesenchymal markers and EMT-TFs (i.e. Vimentin, Slug, Snail, and ZEB1) (Supplemental Figure S1B). A cytokine array, performed on conditioned medium from control (EMTnegative) and EGF-treated (EMT-positive) MDA-MB-468, showed an increase in several factors (Figure 1C-D). The five most overexpressed molecules were Interleukin-8 (IL-8), Interleukin-6 (IL-6), Plasminogen Activator Inhibitor-1 (PAI-1), soluble form of InterCellular Adhesion Molecule-1 (sICAM-1) and Granulocyte Monocyte-Colony Stimulating Factor (GM-CSF). We confirmed their upregulation by RT-qPCR (Figure 1E) and ELISA (Figure 1F) in MDA-MB-468. It is worth mentioning that, if IL-8, Il-6, GM-CSF and PAI-1 are secreted molecules, ICAM-1 can be either transmembrane or soluble, due to both alternative splicing and protein shedding [40]. Primers recognizing all forms of ICAM-1 were used, while only soluble sICAM-1 was detected by ELISA. Similar regulations were obtained with A549 cells (Figure S1C and S1D), although sICAM-1 secretion could not be detected. 
The expression of the five factors of interest was also assessed in well-known EMT-negative (vimentin-negative, E-cadherin-positive) and EMT-positive (vimentin-positive, E-cadherinnegative) breast cancer cell lines. Supporting our results on the inducible models, higher mRNA expression levels and higher protein secretion levels of IL-8, IL-6, PAI-1, (s)ICAM-1 and GM-CSF were detected in EMT-positive human breast cancer cell lines (MDA-MB-231, Hs578T, BT-549) compared to epithelial-like cell lines (MCF7 and T47D) (Figure 2A-B).

To investigate the association between EMT and secreted factors in vivo, MDA-MB-468 cells were used to induce tumors in SCID mice. These cells undergo EMT in vivo [21] and tumors indeed contained vimentin-positive and vimentin-negative zones (Figure 2C) which were microdissected (Figure 2D). IL-6 and PAI-1 mRNA expression was significantly higher in vimentin-positive compared to vimentin-negative zones (Figure 2E). IL-8 mRNA tended to be higher in the vimentin-positive compartment, although this did not reach statistical significance. No change in ICAM-1 mRNA expression was observed. GM-CSF was not detectable, in accordance with its low expression level in vitro.

To establish a functional contribution of EMT pathways in soluble factor regulation, we investigated the well described EMT-associated transcription factors Slug and Snail in the process. Indeed, their expression was increased upon EMT induction in MDA-MB-468 (Figure 3A). As we observed that Snail siRNA knockdown affected Slug expression and vice versa (data not shown), we knocked both genes down. Though some variations were observed between the different control siRNA sequences used, combined siRNA repression of Slug and Snail strongly and reproducibly inhibited mRNA levels of IL-8, IL-6 and PAI-1 in EGF-treated MDA-MB-468 (Figure 3A). Similar results were observed in A549 (Figure S2). Inversely, ectopic expression of a degradation-resistant form of Snail, Snail-6SA [41] increased mRNA levels of all five factors, reaching significance for IL-6 and PAI-1 in MDAMB-468 (Figure 3B) and for IL-8 and IL-6 in A549 (Supplemental Figure S2B). Altogether, 
these results suggest a functional contribution of EMT pathways, and particularly of Snail, in regulating expression of the soluble factors of interest, even though other transcription factors are most likely involved also.

\section{EMT-positive cell-conditioned medium is angiogenic and recruits myeloid derived suppressor cells (MDSCs)}

The above results prompted us to investigate the functional consequences of these factors on host cell recruitment in vivo. Subcutaneously inserted sponges, previously soaked in conditioned medium of EMT-positive cells or EMT-negative cells, were collected after 3 and 21 days to analyze inflammation and angiogenesis, respectively. After 21 days, blood vessels were detected by CD31 immunostaining (Figure 4A) and blood vessel density was determined by computer-assisted quantification. Sponges soaked in conditioned medium from EGF-treated MDA-MB-468 were infiltrated by a higher number of blood vessels

compared to sponges soaked in control conditioned medium (Figure 4B). Direct effects of EGF in the sponge assay were excluded by the extemporaneous addition of EGF in the control conditioned medium $(\mathrm{C}+\mathrm{E})$. Similar results were obtained with A549 cells (Supplemental Figure S3A-B). To characterize the specific effect of each soluble factor, conditioned medium from EGF-treated MDA-MB-468 was depleted of each factor of interest independently before performing the sponge assay. Depletion of IL-8, IL-6 and GM-CSF decreased sponge vascularization (Figure 4C). PAI-1 or sICAM-1 depletion had no significant effect (though a trend to a decrease of vascularization is observed after sICAM-1 depletion). Confirming the enhanced pro-angiogenic activity observed in the sponge assay, conditioned medium from EGF-treated MDA-MB-468 significantly increased vessel sprouting in a rat aortic ring assay (Figure 4D-F). 
To characterize this EMT-associated pro-angiogenic activity further, conditioned medium was tested for chemotactic activity on HUVEC cells, where medium from EGF-treated MDA-MB-468 cells increased migration compared to control conditions ( $\mathrm{C}$ and $\mathrm{C}+\mathrm{E})$ (Figure 4G), but did not affect HUVEC proliferation (data not shown). Inhibition with specific blocking antibodies showed that IL-6 and PAI-1 are necessary for HUVEC migration (Figure $4 \mathrm{H})$. Surprisingly, inhibition of ICAM-1 or IL-8, which are well-known angiogenic compounds [42-45], did not affect migration, though the efficiency of blocking antibodies was validated using recombinant IL-8 and ICAM-1 proteins (Supplemental Figure S4). Taken together, these results suggest that IL-6, IL-8, PAI-1, ICAM-1 and GM-CSF are functional secreted mediators of EMT-induced pro-angiogenic activity in our models.

To investigate the impact of EMT-induced cytokines on inflammatory cell recruitment, we took advantage of the 3 day-sponge model. Sponge dissociation followed by FACS analysis enabled us to characterize the infiltration of the sponge by macrophages and myeloid cells. F4/80 staining revealed that macrophages are not markedly recruited (data not shown). We thus studied the recruitment of other cell types and, because of their immunosuppressive, prometastatic activity $[46,47]$, we examined $\mathrm{CD} 11 \mathrm{~b}^{+} \mathrm{GR} 1^{+}$myeloid-derived suppressor cells (MDSCs). $\mathrm{CD} 11 \mathrm{~b}^{+} \mathrm{GR} 1^{+}$cells, represent a heterogeneous group of immature myeloid cells of granulocytic $\left(\mathrm{CD} 11 \mathrm{~b}^{+} \mathrm{Ly}_{6 \mathrm{G}} \mathrm{h}^{\text {high }}\right)$ or monocytic $\left(\mathrm{CD} 11 \mathrm{~b}^{+}\right.$Ly6 $\left.\mathrm{C}^{\text {high }}\right)$ morphology. Staining for Ly6G and Ly6C (two epitopes of the GR1 surface receptor) showed that $76 \%$ of cells infiltrating the sponge were granulocytic $\left(\mathrm{CD} 11 \mathrm{~b}^{+}\right.$Ly $\left.6 \mathrm{G}^{\text {high }} \mathrm{Ly} 6 \mathrm{C}^{\text {low }}\right)$, while $\left(\mathrm{CD} 11 \mathrm{~b}^{+} \mathrm{Ly}_{6 \mathrm{G}^{-}}\right.$ ${ }^{\text {/low }}$ Ly6 $\mathrm{C}^{\text {high }}$ ) monocytic cells were less frequent (1.6\%) (Figure 5A). To compare infiltration of this myeloid population in EMT-negative and EMT-positive groups further, and because the dissociation technique of the sponges did not reach an acceptable level of reproducibility to perform quantitative analyses by FACS, we performed immunofluorescent staining on frozen sections cut across the sponges (Figure 5B). Supporting the FACS results, 
immunostaining showed infiltration by $\mathrm{CD} 11 \mathrm{~b}^{+} \mathrm{GR} 1^{+}$myeloid cells around the sponge (Figure 5B). Moreover, sponges soaked in conditioned medium from EGF-treated MDA-MB468 cells contained a higher relative $\mathrm{CD} 11 \mathrm{~b}^{+} \mathrm{GR} 1^{+}$hotspot surface compared to $\mathrm{C}+\mathrm{E}$ (Figure 5C). Suspecting recruitment of these cells from the bone marrow, we correspondingly showed by FACS that mice bearing sponges soaked in EMT-positive conditioned medium contained a decreased proportion of $\mathrm{CD} 11 \mathrm{~b}^{+} \mathrm{Ly} 6 \mathrm{G}^{\text {high }} \mathrm{Ly} 6 \mathrm{C}^{\text {low }}$ cells in their bone marrow compared to control mice. Proportions of $\mathrm{CD} 11 \mathrm{~b}^{+} \mathrm{Ly} 6 \mathrm{C}^{\text {high }} \mathrm{Ly} 6 \mathrm{G}^{-/ \text {low }}$ were unchanged in the bone marrow (Figure 5D).

\section{EMT markers relate to increased angiogenesis and tumor infiltration by myeloid cells in triple-negative breast cancers}

Based on the aforementioned results in vitro and in animal models, we examined the potential relationship between EMT, angiogenesis and myeloid cell recruitment in 40 triple-negative breast cancers. The triple-negative subtype was selected because of the well-described enrichment of EMT markers in this subtype compared to all breast cancer types [30]. Indeed, 20 of the 40 samples displayed at least $10 \%$ vimentin-positive cancer cells (equaling to a score of 2) (Figure 6). Vimentin expression by cancer cells was further associated with the presence of other EMT features such as enhanced Snail and a diminution of membraneassociated E-cadherin (Figure 6A and Table 1). Most interestingly, vimentin expression by at least $10 \%$ of cancer cells was associated with increased density of CD105-positive blood vessels, compared to tumors containing less than $10 \%$ vimentin-positive cancer cells (Figure $6 \mathrm{~B}$ and Table 2). Likewise and corroborating our findings suggesting an EMT-mediated recruitment of MDSCs, the presence of EMT markers in triple-negative breast cancers was 
associated with increased tumor infiltration by CD33-positive myeloid cells (Figure 6B and Table 2).

\section{Discussion}

Although sound evidence has accumulated linking EMT to cancer progression in breast cancer patients $[25,26,28,30]$, corroborated by in vitro models $[29,46]$ and animal experiments [21, 24], mechanisms connecting EMT to tumor-stroma interaction and cancer progression remain elusive. We show that EMT phenotypes relate to increased expression of a panel of soluble mediators (IL-8, IL-6, sICAM-1, PAI-1 and GM-CSF) in several cellular systems. These factors are consistently increased in two cell lines following growth factor treatment and strongly expressed in cell lines displaying endogenous EMT traits. Our results are pertinently supported by a few data linking EMT-signaling and specific cytokine secretion. The association between EMT features and IL-8 has already been reported by us and others in breast [47] and colorectal carcinoma cell lines [48]. Clinically, EMT features were found enriched in IL-8-positive hepatocellular carcinoma tissues [49]. Regarding the regulation of other cytokines through EMT, data are scarce. PAI-1 expression is nevertheless induced during EMT in Ras-transformed keratinocytes (HaCaT II-4) [50] and mesenchymallike breast cancer cells secrete high amounts of GM-CSF [51]. Although some data implicate membrane bound ICAM-1 in accelerating TGF- $\beta$-induced EMT in renal cells in the presence of its ligand (LFA-1) on the surface of monocytes [52, 53], no data have clearly linked sICAM-1 expression to EMT.

Conversely, certain chemokines also act as EMT inducers. Independent studies have shown that IL-8 [54] and IL-6 [55] act as key mediators of EMT induction and maintenance in several cancer cell lines [54]. Also, a functional role of PAI-1 in the modulation of EMT programs has been reported in Ras-induced EMT of HaCAT II cells [50] and in a model of 
EMT-induced lung fibrosis [56]. In the latter, PAI-1 knockdown inhibited TGF- $\beta$-triggered EMT in murine epithelial cells. Taken together, these data suggest that induction of IL-8, IL6 and PAI-1 might create a positive regulatory loop to maintain EMT.

Our findings also indicate that EMT-associated cytokines are regulated by the EMTtranscription factor Snail, even though other transcription factors are most likely involved. Supporting our results, ectopic expression of Snail in the canine renal MDCK cell line accentuates IL-6 and IL-8 increase upon IL-1 $\beta$ stimulation [57] and Snail expression in head and neck carcinoma cells enhances IL-6 and IL-8 expression [58]. Functional inhibition of Snail by ectopic expression of a dominant negative form in breast cancer cells decreases PAI1 expression [59]. Other EMT-transcription factors such as Brachury [54] or Twist [60] have also been shown to promote IL-8 expression. Our previous data have also shown increased IL-8 expression in breast cancer cell lines depending on EMT-induced ZO-1 delocalization [47]. Taken together, the data support the involvement of various EMT pathways in regulating expression of specific soluble mediators by cancer cells. Our results, consistently identifying the 5 factors of interest modulated through a major EMT transcription factor such as Snail in different cellular systems, support their relevance as target genes of EMT.

Our results further show that EMT creates a pro-angiogenic context. Data obtained on triple negative breast cancers indicate a correlation between the presence of EMT features and increased angiogenesis. Corroborating these observations, conditioned medium from EMT-positive cells increases angiogenesis in vivo in the sponge assay, stimulates vessel sprouting from rat aortic rings ex vivo and enhances HUVEC cell migration in vitro. In agreement with these observations, modifying the expression of EMT actors, including Snail, in different cell lines modifies their angiogenic properties [61-63]. We further show that EMT-induced IL-6 and PAI-1 appear to be the most important players in HUVEC chemotaxis, while IL-8, IL-6-and GM-CSF seem necessary for angiogenesis in vivo. This 
apparent discrepancy between in vitro and in vivo models might be accounted for by the welldescribed indirect effects of some of the soluble factors of interest on angiogenesis. In agreement with our observations, a multifaceted effect of several soluble factors has been reported. Nilsson and colleagues [64] have shown that IL-6 stimulates angiogenesis in the sponge assay. Furthermore, IL-6 stimulates HUVEC cell proliferation, tubule formation and vessel sprouting in aortic ring assays [65] and fibroblast-derived IL-6 was recently shown to promote angiogenesis in colorectal tumors [66]. Regarding PAI-1, it has been shown to exert dual effects on angiogenesis, contextually either stimulating or inhibiting angiogenesis [6769]. IL-8 is a well-known pro-angiogenic cytokine, which acts both directly on endothelial cells $[43,44]$ and indirectly by recruiting pro-angiogenic inflammatory cells $[33,70]$. Taken together, our results demonstrate, on one hand, that EMT relates to increased angiogenesis in triple-negative breast cancer and, on the other hand, that EMT-regulated soluble factors are angiogenic.

Examining the cohort of triple-negative breast cancers allowed us to correlate the presence of EMT markers to increased tumor infiltration by CD33-positive myeloid cells. Additionally, in the sponge assay model, sponges containing conditioned medium from EMT-positive cells were invaded by more $\mathrm{CD} 11 \mathrm{~b}^{+} \mathrm{GR} 1^{+}$myeloid cells compared to control sponges. EMTpositive sponges are especially infiltrated by granulocytic MDSCs. Accordingly, bone marrows from sponge-bearing mice showed decreased proportions of CD $11 \mathrm{~b}^{+} \mathrm{Ly}_{6} \mathrm{G}^{\mathrm{hi}} \mathrm{Ly} 6 \mathrm{C}^{\mathrm{low}}$ cells in the EMT-positive group, whereas the $\mathrm{CD} 11 \mathrm{~b}^{+} \mathrm{Ly} 6 \mathrm{C}^{\mathrm{hi}} \mathrm{Ly} 6 \mathrm{G}^{-/ \mathrm{low}}$ proportion was unchanged. The clinical importance of MDSCs has been revealed by trials showing their circulating levels are not only predictive of survival in metastatic breast cancer patients [71] but also correlated to tumor burden and the number of CTCs [72]. It is also interesting to note that little data today suggest that MDSCs promote not only EMT and cancer cell 
dissemination [73] but also angiogenesis [74]. Most interestingly, immunotherapy combined with anti-angiogenic low-dose anti-VEGFR2 monoclonal antibody decreases tumor infiltration by MDSCs and increases survival in breast cancer-bearing mice [75].

Our results suggest that conditioned medium from EMT-positive cells is able to attract MDSCs. Supportively, pieces of evidence link several EMT-regulated soluble factors to MDSC biology. First, IL-6 and GM-CSF are used for in vitro generation of MDSCs from hematopoietic stem cells. Second, clinical trials have shown that high levels of tumor-derived GM-CSF are associated with infiltration of the tumor by MDSCs [76, 77]. Third, in mice expressing IL-8 under the control of its human promoter, inflammatory and neoplastic sites are infiltrated by a higher number of MDSCs [70]. Taken together, our results reveal that EMT programs regulate a consistent panel of soluble mediators that promote angiogenesis and MDSC recruitment, both of which may independently or synergistically elaborate a milieu permissive for tumor spread. Emphasizing the clinical relevance of our observations, we identified an EMT-positive, angiogenic and myeloid cell-rich subgroup of TNBCs, better characterization of which constitutes a major current clinical concern. 


\section{Acknowledgment}

This work was supported by grants from the Fonds de la Recherche Scientifique Médicale, the Fonds de la Recherche Scientifique - FNRS (F.R.S.-FNRS, Belgium), the Foundation against Cancer (foundation of public interest, Belgium), and Partenariat Hubert CurienTournesol, the Fonds spéciaux de la Recherche (University of Liège), the Centre Anticancéreux près l'Université de Liège, the Fonds Léon Fredericq (University of Liège), the Direction Générale Opérationnelle de l'Economie, de l'Emploi et de la Recherche from the S.P.W. (Région Wallonne, Belgium). CG is a Senior Research Associate at the F.R.SFNRS, MSC is a Research Fellow at the F.R.S.-FNRS. We thank Emilie Fereysen, Isabelle Dasoul, Marie Dehuy, Guy Roland, Laure Volders and Nathalie Lefin for technical assistance. We thank the GIGA Bioinformatics Platform for providing access to computing servers and to the Cytomine software, and the GIGA-Imaging and Microdissection platform for providing access to FACSCanto II (BD) and LMD7000 microdissector (Leica).

\section{Statement of author contributions}

MSC and CG conceived and carried out experiments. $\mathrm{MB}, \mathrm{PH}$ and LS carried out experiments. JL, MP and PB provided and analyzed staining on human samples. SB analyzed images. MSC and NL carried out in vivo experiments. CE helped with the development of sponge assays. All authors, including PD, JMF and AN were involved in writing the paper and had final approval of the submitted and published versions. 


\section{References}

1. Thiery JP, Acloque $\mathrm{H}$, Huang RY, et al. Epithelial-mesenchymal transitions in development and disease. Cell 2009; 139: 871-890.

2. Kalluri R, Weinberg RA. The basics of epithelial-mesenchymal transition. J Clin Invest 2009; 119: $1420-1428$.

3. Thiery JP, Lim CT. Tumor dissemination: an EMT affair. Cancer Cell 2013; 23: 272-273.

4. Zavadil J, Bottinger EP. TGF-beta and epithelial-to-mesenchymal transitions. Oncogene 2005; 24: 5764-5774.

5. Xu J, Lamouille S, Derynck R. TGF-beta-induced epithelial to mesenchymal transition. Cell Research 2009; 19: 156-172.

(1)

6. Yang J, Weinberg RA. Epithelial-mesenchymal transition: at the crossroads of development and tumor metastasis. Dev Cell 2008; 14: 818-829.

7. Peinado $\mathrm{H}$, Olmeda D, Cano A. Snail, Zeb and bHLH factors in tumour progression: an alliance against the epithelial phenotype? Nat Rev Cancer 2007; 7: 415-428.

8. de Herreros AG, Peiro $S$, Nassour $M$, et al. Snail family regulation and epithelial mesenchymal transitions in breast cancer progression. Journal of Mammary Gland Biology \& Neoplasia 2010; 15: 135-147.

9. Miyoshi A, Kitajima $Y$, Sumi K, et al. Snail and SIP1 increase cancer invasion by upregulating MMP family in hepatocellular carcinoma cells. Br J Cancer 2004; 90: 1265-1273.

10. Bindels $S$, Mestdagt $M$, Vandewalle $C$, et al. Regulation of vimentin by SIP1 in human epithelial breast tumor cells. Oncogene 2006; 25: 4975-4985.

11. Wang WS, Yang XS, Xia M, et al. Silencing of twist expression by RNA interference suppresses epithelial-mesenchymal transition, invasion, and metastasis of ovarian cancer. Asian Pac $J$ Cancer Prev 2012; 13: 4435-4439.

12. De Craene B, Berx G. Regulatory networks defining EMT during cancer initiation and progression. Nat Rev Cancer 2013; 13: 97-110.

13. Chiang C, Ayyanathan K. Snail/Gfi-1 (SNAG) family zinc finger proteins in transcription regulation, chromatin dynamics, cell signaling, development, and disease. Cytokine \& Growth Factor Reviews 2013; 24: 123-131.

14. Blanco MJ, Moreno-Bueno G, Sarrio D, et al. Correlation of Snail expression with histological grade and lymph node status in breast carcinomas. Oncogene 2002; 21: 3241-3246.

15. Blechschmidt K, Sassen S, Schmalfeldt B, et al. The E-cadherin repressor Snail is associated with lower overall survival of ovarian cancer patients. Br J Cancer 2008; 98: 489-495.

16. Du F, Nakamura $\mathrm{Y}, \mathrm{Tan} \mathrm{TL}$, et al. Expression of snail in epidermal keratinocytes promotes cutaneous inflammation and hyperplasia conducive to tumor formation. Cancer Res 2010; 70: $10080-10089$.

17. Kudo-Saito C, Shirako $\mathrm{H}$, Takeuchi $\mathrm{T}$, et al. Cancer metastasis is accelerated through immunosuppression during Snail-induced EMT of cancer cells. Cancer Cell 2009; 15: 195-206.

18. Peinado $\mathrm{H}$, Marin $\mathrm{F}$, Cubillo $\mathrm{E}$, et al. Snail and $\mathrm{E} 47$ repressors of $\mathrm{E}$-cadherin induce distinct invasive and angiogenic properties in vivo. J Cell Sci 2004; 117: 2827-2839.

19. Hwang WL, Yang MH, Tsai ML, et al. SNAIL regulates interleukin-8 expression, stem cell-like activity, and tumorigenicity of human colorectal carcinoma cells. Gastroenterology 2011; 141: 279-291, 291 e271-275.

20. Bonnomet A, Brysse A, Tachsidis A, et al. Epithelial-to-mesenchymal transitions and circulating tumor cells. Journal of Mammary Gland Biology \& Neoplasia 2010; 15: 261-273.

21. Bonnomet A, Syne L, Brysse A, et al. A dynamic in vivo model of epithelial-to-mesenchymal transitions in circulating tumor cells and metastases of breast cancer. Oncogene 2012. 
22. Christiansen JJ, Rajasekaran AK. Reassessing epithelial to mesenchymal transition as a prerequisite for carcinoma invasion and metastasis. Cancer Res 2006; 66: 8319-8326.

23. Tsai JH, Donaher JL, Murphy DA, et al. Spatiotemporal regulation of epithelial-mesenchymal transition is essential for squamous cell carcinoma metastasis. Cancer Cell 2012; 22: 725736.

24. Chaffer $\mathrm{CL}$, Brennan JP, Slavin JL, et al. Mesenchymal-to-epithelial transition facilitates bladder cancer metastasis: role of fibroblast growth factor receptor-2. Cancer Res 2006; 66: 11271-11278.

25. Aktas B, Tewes $M$, Fehm $T$, et al. Stem cell and epithelial-mesenchymal transition markers are frequently overexpressed in circulating tumor cells of metastatic breast cancer patients. Breast Cancer Res 2009; 11: R46.

26. Yu M, Bardia A, Wittner BS, et al. Circulating breast tumor cells exhibit dynamic changes in epithelial and mesenchymal composition. Science 2013; 339: 580-584.

27. Lesniak D, Sabri S, Xu Y, et al. Spontaneous epithelial-mesenchymal transition and resistance to HER-2-targeted therapies in HER-2-positive luminal breast cancer. PLoS One 2013; 8: e71987.

28. Sarrio D, Rodriguez-Pinilla SM, Hardisson D, et al. Epithelial-mesenchymal transition in breast cancer relates to the basal-like phenotype. Cancer Res 2008; 68: 989-997.

29. Taube JH, Herschkowitz JI, Komurov $\mathrm{K}$, et al. Core epithelial-to-mesenchymal transition interactome gene-expression signature is associated with claudin-low and metaplastic breast cancer subtypes. Proc Natl Acad Sci U S A 2010; 107: 15449-15454.

30. Sethi $S$, Sarkar FH, Ahmed $Q$, et al. Molecular markers of epithelial-to-mesenchymal transition are associated with tumor aggressiveness in breast carcinoma. Trans/ Oncol 2011; 4: 222-226.

31. Herold Cl, Anders CK. New targets for triple-negative breast cancer. Oncology 2013; 27: 846854.

32. Singh S, Sadanandam A, Singh RK. Chemokines in tumor angiogenesis and metastasis. Cancer \& Metastasis Reviews 2007; 26: 453-467.

33. Waugh DJ, Wilson C. The interleukin-8 pathway in cancer. Clin Cancer Res 2008; 14: 67356741.

34. Gerber PA, Hippe A, Buhren BA, et al. Chemokines in tumor-associated angiogenesis. Biol Chem 2009; 390: 1213-1223.

35. Wilson J, Balkwill F. The role of cytokines in the epithelial cancer microenvironment. Seminars in Cancer Biology 2002; 12: 113-120.

36. Chavey C, Bibeau F, Gourgou-Bourgade $S$, et al. Oestrogen receptor negative breast cancers exhibit high cytokine content. Breast Cancer Res 2007; 9: R15.

37. Soria G, Ben-Baruch A. The inflammatory chemokines CCL2 and CCL5 in breast cancer. Cancer Letters 2008; 267: 271-285.

38. Lenoir B, Wagner DR, Blacher S, et al. Effects of adenosine on lymphangiogenesis. PLoS One 2014; 9: e92715.

39. Berndt $S$, Blacher $S$, Perrier d'Hauterive $S$, et al. Chorionic gonadotropin stimulation of angiogenesis and pericyte recruitment. Journal of Clinical Endocrinology \& Metabolism 2009; 94: 4567-4574.

40. Ramos TN, Bullard DC, Barnum SR. ICAM-1: isoforms and phenotypes. J Immunol 2014; 192: 4469-4474.

41. Zhou BP, Deng J, Xia W, et al. Dual regulation of Snail by GSK-3beta-mediated phosphorylation in control of epithelial-mesenchymal transition. Nat Cell Biol 2004; 6: 931940. 
42. Heidemann J, Ogawa $H$, Dwinell MB, et al. Angiogenic effects of interleukin 8 (CXCL8) in human intestinal microvascular endothelial cells are mediated by CXCR2. $J$ Biol Chem 2003; 278: 8508-8515.

43. Koch AE, Polverini PJ, Kunkel SL, et al. Interleukin-8 as a macrophage-derived mediator of angiogenesis. Science 1992; 258: 1798-1801.

44. Li A, Dubey S, Varney ML, et al. IL-8 Directly Enhanced Endothelial Cell Survival, Proliferation, and Matrix Metalloproteinases Production and Regulated Angiogenesis. The Journal of Immunology 2003: 3369-3376.

45. Gho YS, Kleinman HK, Sosne G. Angiogenic activity of human soluble intercellular adhesion molecule-1. Cancer Res 1999; 59: 5128-5132.

46. Wilkins-Port CE, Higgins PJ. Regulation of extracellular matrix remodeling following transforming growth factor-beta1/epidermal growth factor-stimulated epithelialmesenchymal transition in human premalignant keratinocytes. Cells Tissues Organs 2007; 185: 116-122.

47. Brysse $A$, Mestdagt $M$, Polette $M$, et al. Regulation of CXCL8/IL-8 expression by zonula occludens-1 in human breast cancer cells. Mol Cancer Res 2012; 10: 121-132.

48. Bates RC, DeLeo MJ, 3rd, Mercurio AM. The epithelial-mesenchymal transition of colon carcinoma involves expression of IL-8 and CXCR-1-mediated chemotaxis. Experimental Cell Research 2004; 299: 315-324.

49. Yu J, Ren $X$, Chen $Y$, et al. Dysfunctional activation of neurotensin/IL-8 pathway in hepatocellular carcinoma is associated with increased inflammatory response in microenvironment, more epithelial mesenchymal transition in cancer and worse prognosis in patients. PLoS One 2013; 8: e56069.

50. Freytag J, Wilkins-Port CE, Higgins CE, et al. PAl-1 mediates the TGF-beta1+EGF-induced "scatter" response in transformed human keratinocytes. J Invest Dermatol 2010; 130: 21792190.

51. Su S, Liu Q, Chen J, et al. A positive feedback loop between mesenchymal-like cancer cells and macrophages is essential to breast cancer metastasis. Cancer Cell 2014; 25: 605-620.

52. Morishita $\mathrm{Y}$, Watanabe M, Nakazawa E, et al. The Interaction of LFA-1 onMononuclear Cells and ICAM-1 on Tubular Epithelial Cells Accelerates TGF-b1-Induced Renal EpithelialMesenchymal Transition. PIOS One 2011; 6.

53. Li Q, Liu BC, Lv LL, et al. Monocytes induce proximal tubular epithelial-mesenchymal transition through NF-kappa B dependent upregulation of ICAM-1. J Cell Biochem 2011; 112: 1585-1592.

54. Fernando RI, Castillo MD, Litzinger M, et al. IL-8 signaling plays a critical role in the epithelialmesenchymal transition of human carcinoma cells. Cancer Res 2011; 71: 5296-5306.

55. Sullivan NJ, Sasser AK, Axel AE, et al. Interleukin-6 induces an epithelial-mesenchymal transition phenotype in human breast cancer cells. Oncogene 2009; 28: 2940-2947.

56. Senoo $\mathrm{T}$, Hattori $\mathrm{N}$, Tanimoto $\mathrm{T}$, et al. Suppression of plasminogen activator inhibitor-1 by RNA interference attenuates pulmonary fibrosis. Thorax 2010; 65: 334-340.

57. Lim S, Becker A, Zimmer A, et al. SNAl1-mediated epithelial-mesenchymal transition confers chemoresistance and cellular plasticity by regulating genes involved in cell death and stem cell maintenance. PLoS One 2013; 8: e66558.

58. Lyons JG, Patel V, Roue NC, et al. Snail up-regulates proinflammatory mediators and inhibits differentiation in oral keratinocytes. Cancer Res 2008; 68: 4525-4530.

59. Fabre-Guillevin E, Malo M, Cartier-Michaud A, et al. PAI-1 and functional blockade of SNAI1 in breast cancer cell migration. Breast Cancer Res 2008; 10: R100.

60. Li S, Kendall SE, Raices R, et al. TWIST1 associates with NF-kappaB subunit RELA via carboxylterminal WR domain to promote cell autonomous invasion through IL8 production. BMC Biol 2012; 10: 73. 
61. Fantozzi A, Gruber DC, Pisarsky L, et al. VEGF-mediated angiogenesis links EMT-induced cancer stemness to tumor initiation. Cancer Res 2014; 74: 1566-1575.

62. Abdulkhalek S, Geen $\mathrm{O}$, Brodhagen $\mathrm{L}$, et al. Transcriptional factor snail controls tumor neovascularization, growth and metastasis in mouse model of human ovarian carcinoma. Clinical and Translational Medicine 2014; 3: 28.

63. Olmeda $D$, Jorda $M$, Peinado $H$, et al. Snail silencing effectively suppresses tumour growth and invasiveness. Oncogene 2007; 26: 1862-1874.

64. Nilsson MB, Langley RR, Fidler IJ. Interleukin-6, secreted by human ovarian carcinoma cells, is a potent proangiogenic cytokine. Cancer Res 2005; 65: 10794-10800.

65. Hernandez-Rodriguez J, Segarra M, Vilardell C, et al. Elevated production of interleukin- 6 is associated with a lower incidence of disease-related ischemic events in patients with giantcell arteritis: angiogenic activity of interleukin- 6 as a potential protective mechanism. Circulation 2003; 107: 2428-2434.

66. Nagasaki T, Hara $M$, Nakanishi $H$, et al. Interleukin-6 released by colon cancer-associated fibroblasts is critical for tumour angiogenesis: anti-interleukin-6 receptor antibody suppressed angiogenesis and inhibited tumour-stroma interaction. Br J Cancer 2014; 110: 469-478.

67. Bajou K, Maillard C, Jost $\mathrm{M}$, et al. Host-derived plasminogen activator inhibitor-1 (PAI-1) concentration is critical for in vivo tumoral angiogenesis and growth. Oncogene 2004; 23: 6986-6990.

68. Bajou K, Noel A, Gerard RD, et al. Absence of host plasminogen activator inhibitor 1 prevents cancer invasion and vascularization. Nat Med 1998; 4: 923-928.

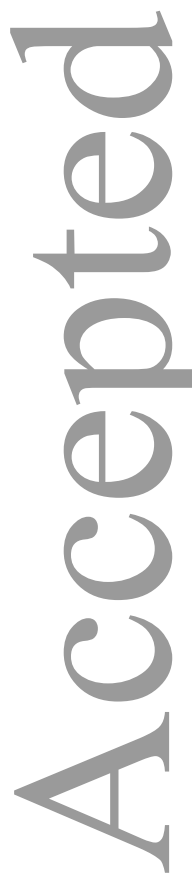

69. Bajou K, Herkenne S, Thijssen VL. PAI-1 mediates the antiangiogenic and profibrinolytic effects of 16K prolactin. 2014; 20: 741-747.

70. Asfaha S, Dubeykovskiy AN, Tomita $\mathrm{H}$, et al. Mice that express human interleukin-8 have increased mobilization of immature myeloid cells, which exacerbates inflammation and accelerates colon carcinogenesis. Gastroenterology 2013; 144: 155-166.

71. Cole S, Montero A, Garret-Mayer E, et al. Elevated Circulating Myeloid Derived Suppressor Cells (MDSC) Are Associated with Inferior Overall Survival (OS) and Correlate with Circulating Tumor Cells (CTC) in Patients with Metastatic Breast Cancer. Cancer Research 2010; 69: 4135-4135.

72. Diaz-Montero CM, Salem ML, Nishimura MI, et al. Increased circulating myeloid-derived suppressor cells correlate with clinical cancer stage, metastatic tumor burden, and doxorubicin-cyclophosphamide chemotherapy. Cancer Immunol Immunother 2009; 58: 4959.

73. Toh B, Wang X, Keeble J, et al. Mesenchymal transition and dissemination of cancer cells is driven by myeloid-derived suppressor cells infiltrating the primary tumor. PLoS Biol 2011; 9: e1001162.

74. Yang L, DeBusk LM, Fukuda K, et al. Expansion of myeloid immune suppressor Gr+CD11b+ cells in tumor-bearing host directly promotes tumor angiogenesis. Cancer Cell 2004; 6: 409421.

75. Huang $\mathrm{Y}$, Yuan J, Righi $\mathrm{E}$, et al. Vascular normalizing doses of antiangiogenic treatment reprogram the immunosuppressive tumor microenvironment and enhance immunotherapy. Proc Natl Acad Sci U S A 2012; 109: 17561-17566.

76. Morales JK, Kmieciak M, Knutson KL, et al. GM-CSF is one of the main breast tumor-derived soluble factors involved in the differentiation of CD11b-Gr1- bone marrow progenitor cells into myeloid-derived suppressor cells. Breast Cancer Research \& Treatment 2010; 123: 3949. 
77. Serafini $\mathrm{P}$, Carbley $\mathrm{R}$, Noonan $\mathrm{KA}$, et al. High-dose granulocyte-macrophage colonystimulating factor-producing vaccines impair the immune response through the recruitment of myeloid suppressor cells. Cancer Res 2004; 64: 6337-6343. 
Figure Legends:

A

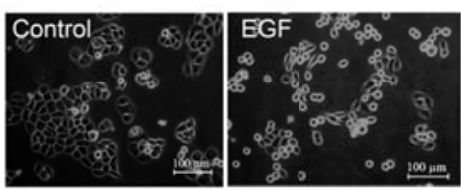

C

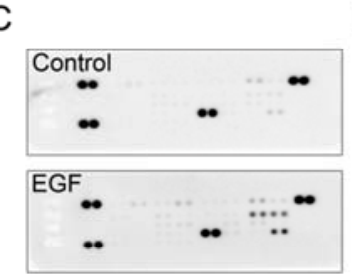

D

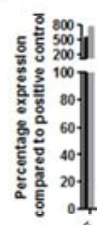

B

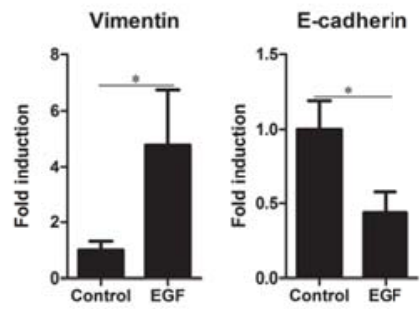

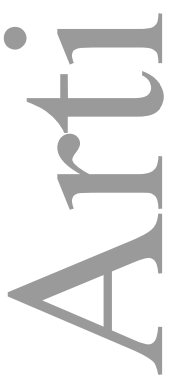
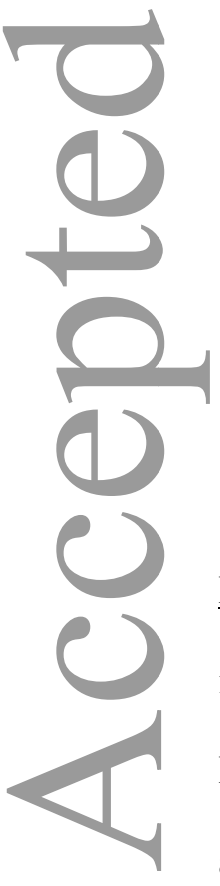

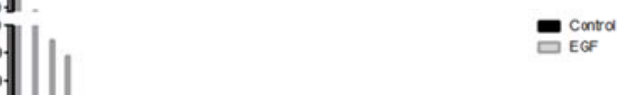

E
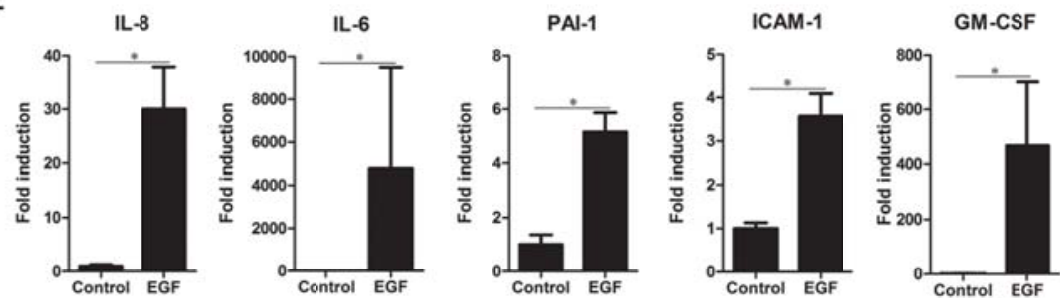

$\mathrm{F}$
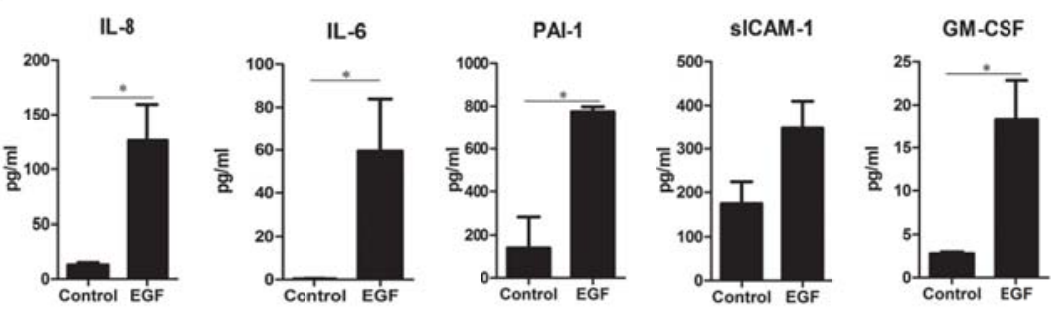

Figure 1. Cytokine expression upon EMT induction in MDA-MB-468 cells. (A) Microscopy images showing morphological changes in MDA-MB-468 cell line upon EGF treatment. (B) RT-qPCR of vimentin and E-cadherin in control or EGF-treated MDA-MB-468 cells. Data are expressed as fold induction in treated cells relative to the controls. (C) Cytokine array membranes after hybridization with conditioned medium from control or EGF-treated MDAMB-468. (D) Quantification of the cytokine array spots in (C) representing levels of each factor in conditioned medium from control (black) or EGF-treated (grey) MDA-MB-468 cells, expressed as percentage of dot intensity compared to internal positive controls. (E-F) 
Analyses of IL-8, IL-6, PAI-1, ICAM-1 and GM-CSF in control or EGF-treated MDA-MB468 by RT-qPCR (E) or ELISA (F). *: p<0.05.

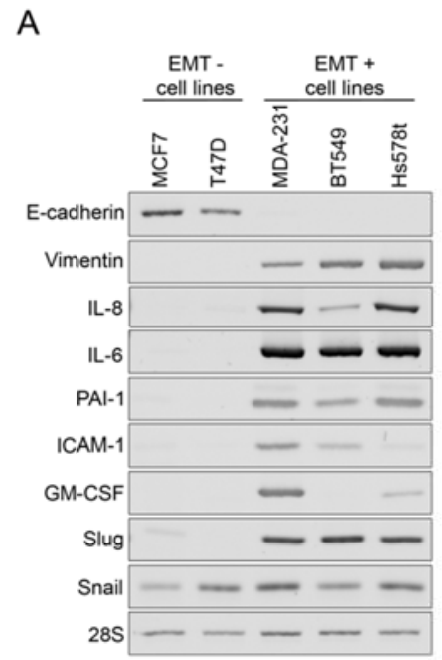

B
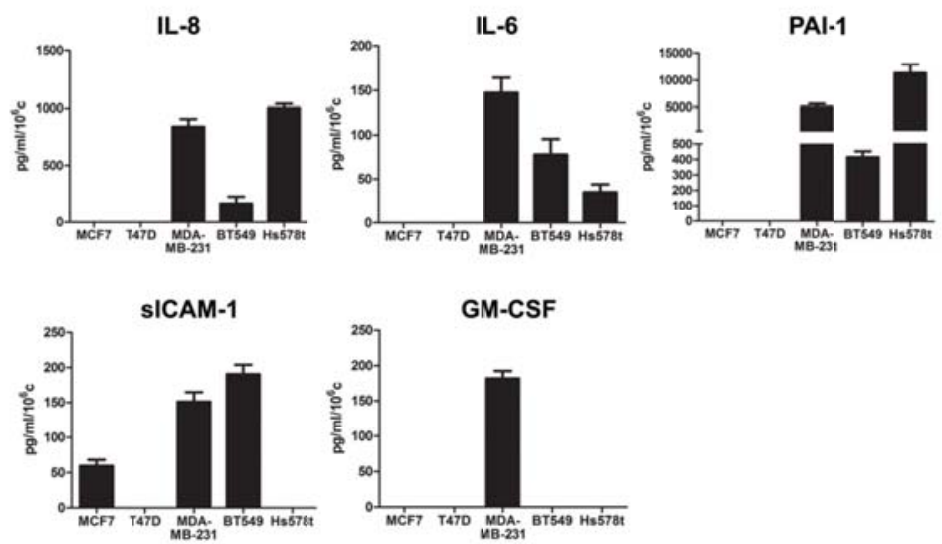

C

D
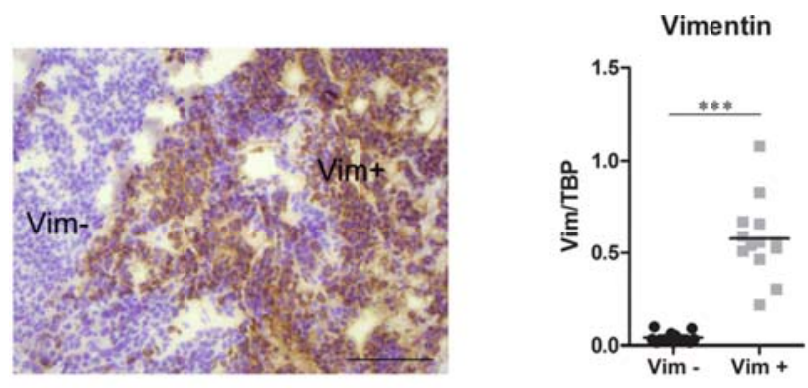

$\mathrm{E}$

IL-8

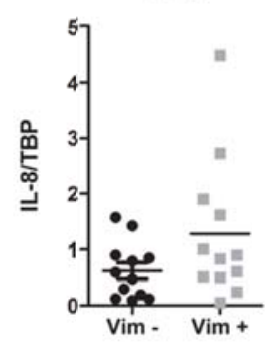

IL-6

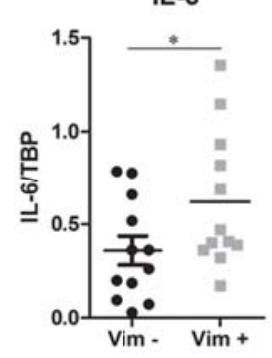

PAl-1

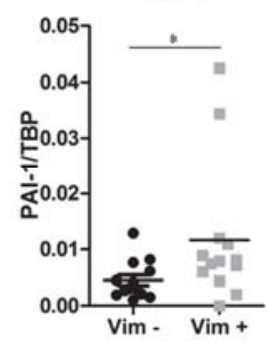

ICAM-1

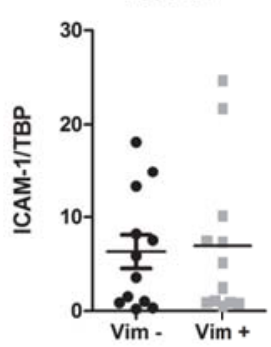

Figure 2. Association between the EMT phenotype and the expression of soluble factors in vitro and in vivo. (A) Endpoint RT-PCR of E-cadherin, vimentin, IL-8, IL-6, PAI-1, ICAM-1 and GM-CSF in a panel of well-known human breast cancer cell lines displaying either 
epithelial-like or endogenous EMT features. (B) ELISA of IL-8, IL-6, PAI-1, sICAM-1 and GM-CSF in the same panel of breast cancer cell lines. (C-E) EMT-related soluble factors in microdissected vimentin-positive and vimentin-negative areas in MDA-MB-468-formed tumors in SCID mice. (C) Human vimentin immunostaining (brown) performed on a section of a MDA-MB-468 tumor formed in SCID mice. Bar: $150 \mu \mathrm{m}$. (D) RT-qPCR of human vimentin on RNA extracted from microdissected vimentin-negative (Vim-) and vimentinpositive $(\mathrm{Vim}+)$ tumor areas. (E) RT-qPCR of RNA extracted from microdissected areas. Each symbol represents a different mouse $(n=13)$. Results are expressed relative to TBP, used as a normalizing gene. ${ }^{*} \mathrm{p}<0.05$ and $* * * \mathrm{p}<0.001$. 

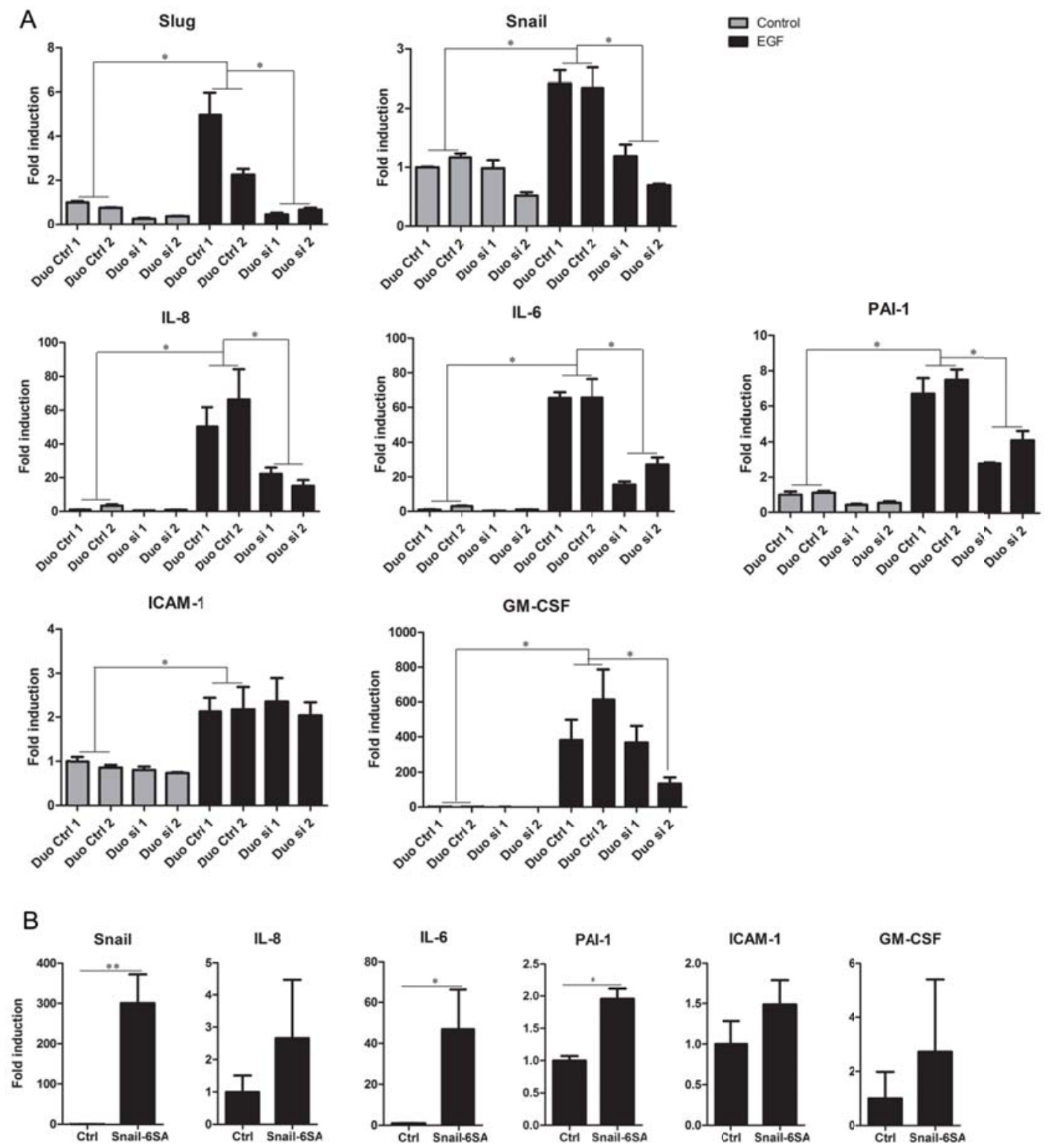

Figure 3. Regulation of soluble factors by Slug and Snail. (A) RT-qPCR of the indicated mRNAs in MDA-MB-468 transfected with two combinations of Snail and Slug siRNA ("Duo si") or two combinations of control siRNAs ("Duo Ctrl"). Data are expressed as fold induction relative to the non-treated control siRNA 1 condition. (B) RT-qPCR analyses of MDA-MB-468 cells transfected with cDNA encoding a degradation-resistant form of Snail (Snail-6SA) or with the corresponding empty vector (Ctrl). *:p<0.05, **:p<0.01. 


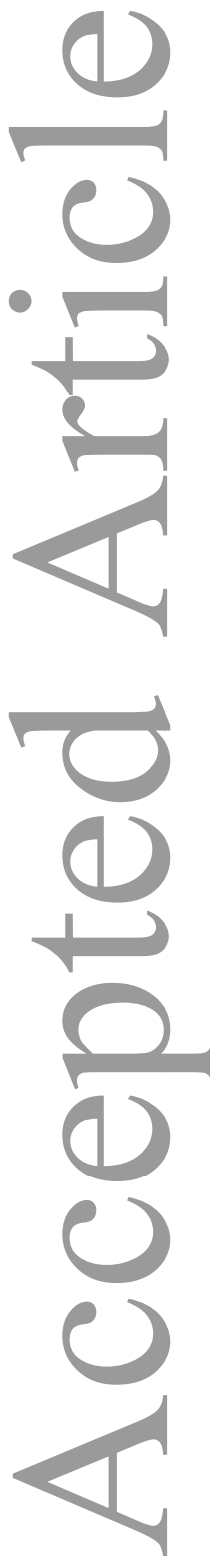

A

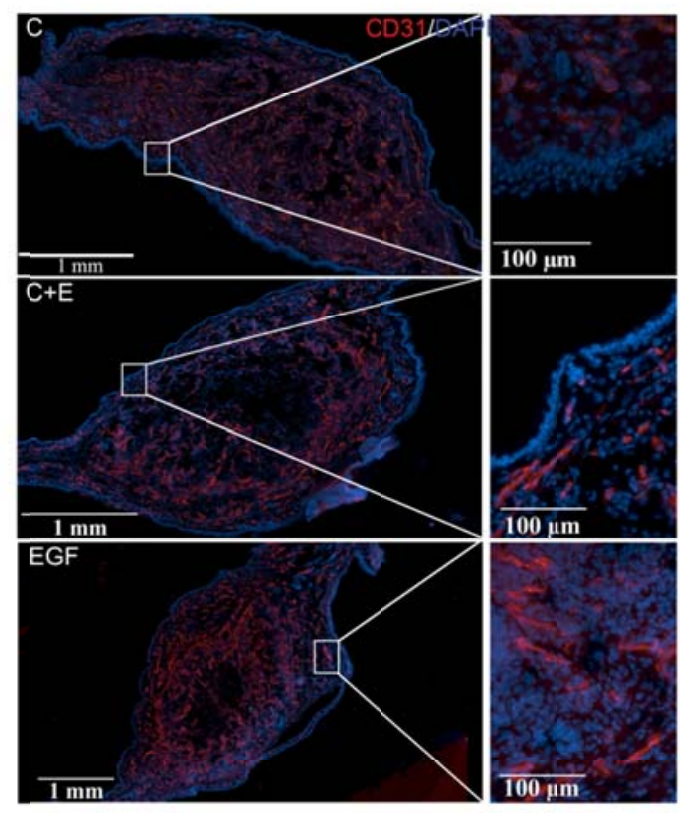

D

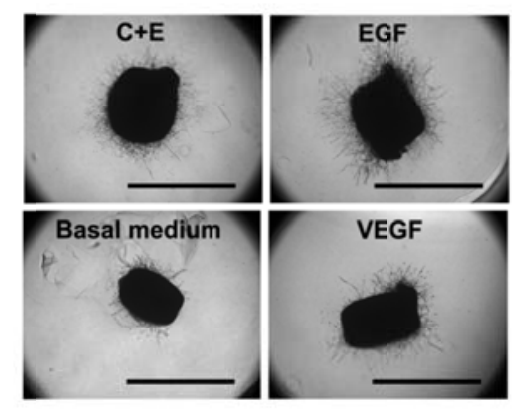

G

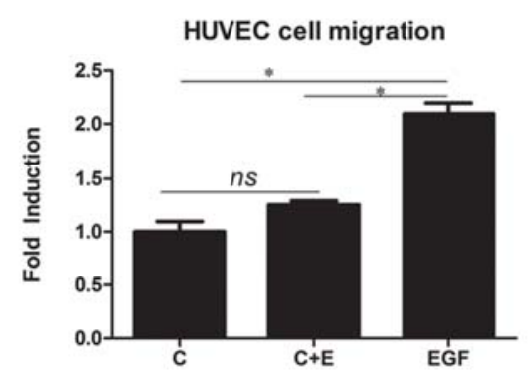

E

$\mathrm{H}$
B

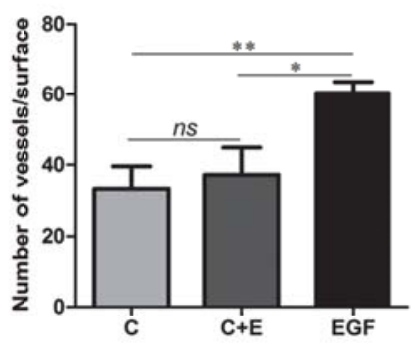

C

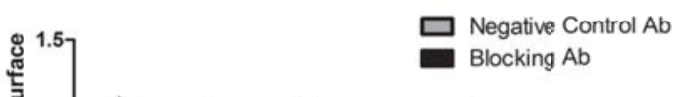

$\mathrm{F}$
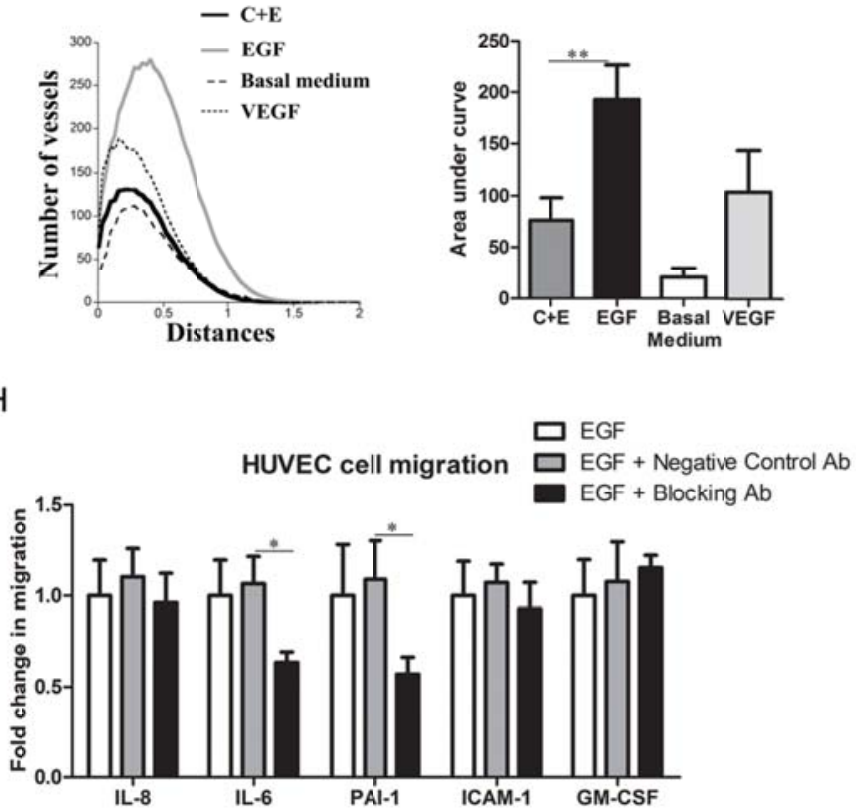
Figure 4. Effect of conditioned medium from EMT-derived cells on angiogenesis. (A) Immunofluorescent staining for CD31 (red, labeling blood vessels) on ear sections containing 3 week-sponges soaked in conditioned medium of non-treated (C) or EGF-treated (EGF) MDA-MB-468. EGF was added to the control conditioned medium to exclude EGF-related effects $(\mathrm{C}+\mathrm{E})$. DAPI (in blue) is used to label nuclei. (B) Computer-assisted quantification of CD31 staining as shown in A representing blood vessel density. Results of one experiment of three independent experiments with $\mathrm{n}=5$ mice $(\mathrm{C}$ and $\mathrm{C}+\mathrm{E})$ and $\mathrm{n}=6(\mathrm{EGF})$ is shown. $(\mathrm{C})$ Computer-assisted quantification of CD31 in a sponge assay performed after immunodepletion of each soluble factor from conditioned medium of EGF-treated MDAMB-468. (D) Microscopy images illustrating 9-day-aortic rings. "Basal medium" and "VEGF" are the negative and positive controls of the experiment. Scale bar: $1 \mathrm{~cm}$. (E) Computer-assisted quantification of images shown in D. (F) Area under curve quantification graphs corresponding to the analyses shown in D. One representative experiment out of 3 is shown. (G) HUVEC chemotaxis assay using conditioned medium from EGF-treated (EGF) or untreated (C) MDA-MB-468. Medium of untreated MDA-MB-468 was supplemented with EGF $(\mathrm{C}+\mathrm{E})$ to exclude any direct effect of EGF. (H) HUVEC chemotaxis assay using conditioned medium of EGF-treated MDA-MB-468 containing blocking antibodies for the indicated factors or corresponding control antibodies. 
A

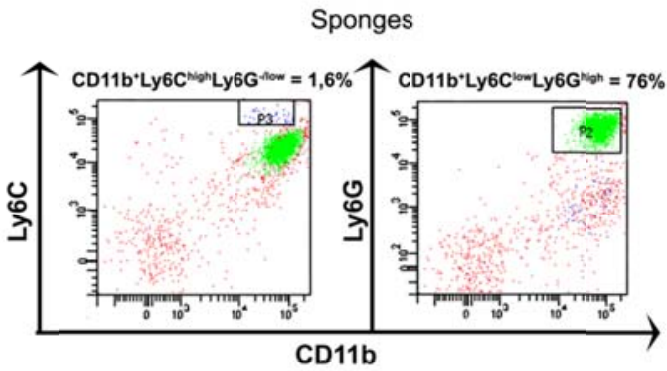

B
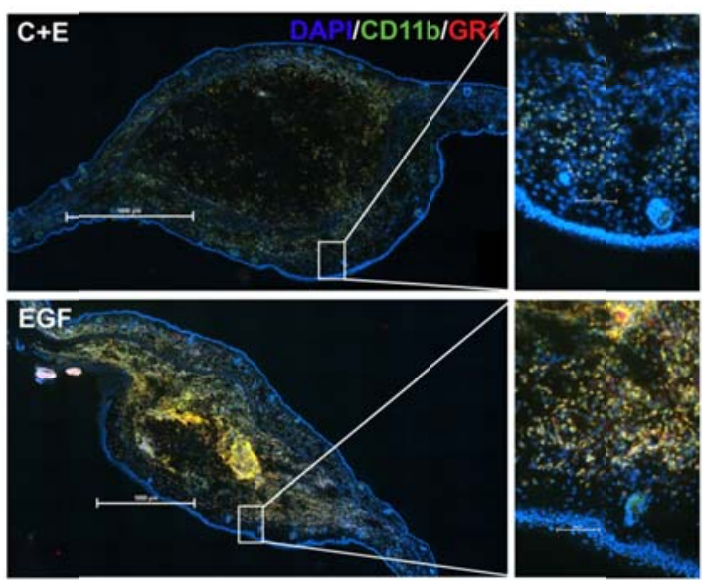

C

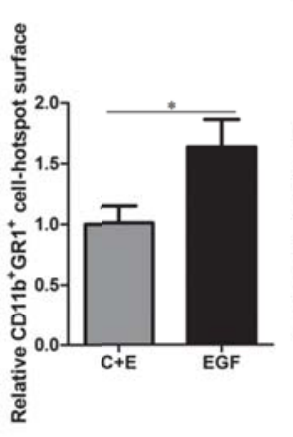

D Marrows

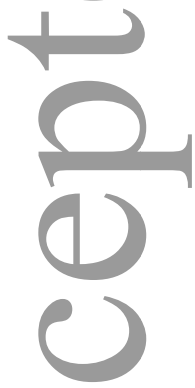

()
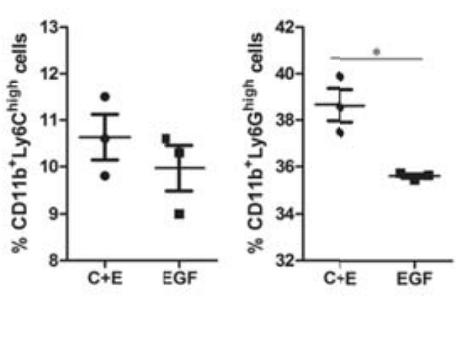

Figure 5. Effect of conditioned medium from EMT-derived cells on myeloid cell recruitment in vivo. (A) FACS analyses of immuno-labeling by CD11b, Ly6G and Ly6C antibodies on cells collected from 3 day-sponges soaked in conditioned medium of EGF-treated MDA-MB468. The CD11b ${ }^{+}$Ly6G ${ }^{\text {hi }}$ Ly6 $C^{\text {low }}$ and CD11b ${ }^{+}$Ly6C ${ }^{\text {hi }}$ Ly6G-/low populations are delineated by boxes (P2 and $\mathrm{P} 3$ respectively) and $\mathrm{CD} 11 \mathrm{~b}^{+} \mathrm{Ly} 6 \mathrm{G}^{\text {hi }} \mathrm{Ly} 6 \mathrm{C}^{\text {low }}$ cells are represented in green. 
(B) CD11b/GR1 fluorescent double staining on ear sections containing 3-day-sponges soaked beforehand in conditioned medium of non-treated or EGF-treated (EGF) MDA-MB-468. EGF was added to the control conditioned medium to exclude EGF-related effects $(\mathrm{C}+\mathrm{E})$. DAPI (blue) is used to label nuclei. (C) Quantification of the relative CD $11 \mathrm{~b}^{+} \mathrm{GR} 1^{+}$hotspot surface on the staining shown in B. A pool of two independent experiments leading to $n=11$ $(\mathrm{C}+\mathrm{E})$ and $\mathrm{n}=13$ (EGF), quantified by two independent observers in double-blind settings is shown. (D) FACS quantification of CD11b, Ly6G and Ly6C immuno-labeling on cells dissociated from bone marrow of sponge-bearing mice. Graphs illustrate the proportions of

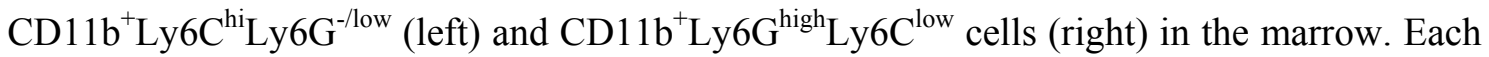
dot represents the pooled analysis of two mice. 


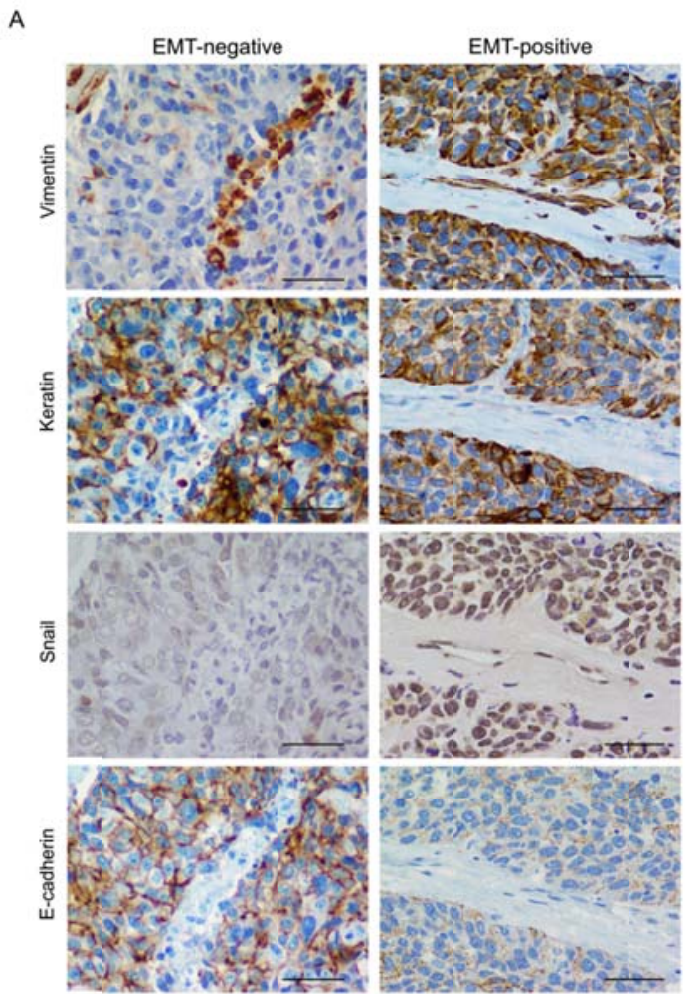

B
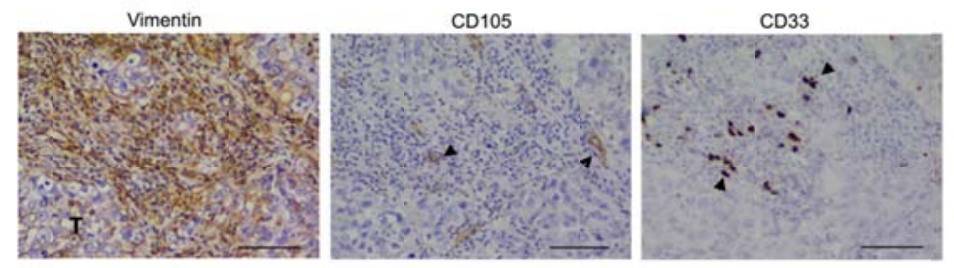

Figure 6. EMT features, blood vessels and myeloid cell recruitment in biopsies of human breast cancers. (A) Illustrative microscopy images of vimentin, keratin, Snail and E-cadherin staining on serial sections in triple-negative breast cancers. EMT-negative (left) and EMTpositive (right) representative areas are shown. Scale bar: $40 \mu \mathrm{m}$ (B) Illustrative images of vimentin, CD105 and CD33 staining on serial sections in a triple negative breast cancer. $\mathrm{T}=$ tumor cluster. Arrows point to blood vessels (CD105) or myeloid cells (CD33). Scale bar: 80 $\mu \mathrm{m}$. 
Table 1: Association between Snail expression, loss of membrane E-Cadherin expression and vimentin expression by cancer cells in triple-negative breast cancers.

\begin{tabular}{|c|c|c|c|}
\hline Variables & $\begin{array}{c}\operatorname{Vim}<10 \% \\
\mathbf{n}=20\end{array}$ & $\begin{array}{c}\operatorname{Vim} \geq 10 \% \\
n=20\end{array}$ & p \\
\hline $\begin{array}{l}\text { Snail expression } \\
\quad<10 \% \\
\geq 10 \%\end{array}$ & $\begin{array}{c}16(67 \%) \\
4(25 \%)\end{array}$ & $\begin{array}{c}8(33 \%) \\
12(75 \%)\end{array}$ & 0.0225 \\
\hline $\begin{array}{l}\text { Loss of E-Cad } \\
\quad<10 \% \\
\geq 10 \% \\
\end{array}$ & $\begin{array}{c}13(76 \%) \\
7(30 \%) \\
\end{array}$ & $\begin{array}{c}4(24 \%) \\
16(70 \%)\end{array}$ & 0.0095 \\
\hline
\end{tabular}


Table 2: CD105 and CD33 expression are associated with vimentin expression by cancer cells in triple-negative breast cancers.

\begin{tabular}{|lccc|}
\hline \multicolumn{1}{|c}{ Variables } & $\begin{array}{c}\text { Vim }<\mathbf{1 0} \% \\
\mathbf{n}=\mathbf{2 0}\end{array}$ & $\begin{array}{c}\text { Vim } \geq \mathbf{1 0 \%} \\
\mathbf{n}=\mathbf{2 0}\end{array}$ & $\mathbf{p}$ \\
\hline CD105 expression & & & \\
Low & $17(71 \%)$ & $7(29 \%)$ & $\mathbf{0 . 0 0 3 1}$ \\
High & $3(19 \%)$ & $13(81 \%)$ & \\
\hline CD33 expression & & & \\
Low & $16(64 \%)$ & $9(36 \%)$ & $\mathbf{0 . 0 4 8 4}$ \\
High & $4(27 \%)$ & $11(73 \%)$ & \\
\hline
\end{tabular}
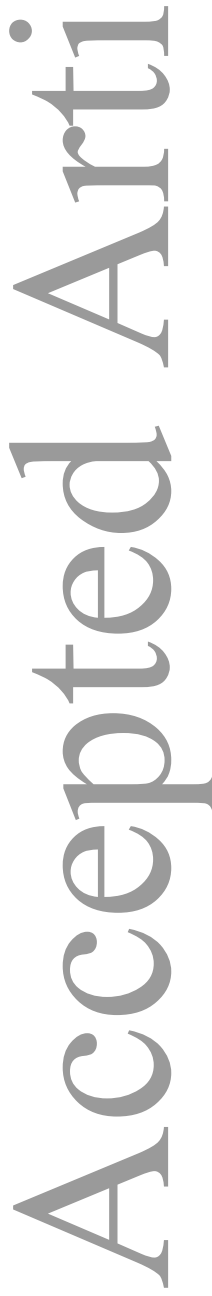